\title{
EXPERIMENTAL STUDIES ON IN-PLANE PERFORMANCE OF PLASTERBOARD SHEATHED CEILING DIAPHRAGMS
}

\author{
Angela Liu', Minghao $\mathrm{Li}^{2}$ and Roger Shelton ${ }^{3}$
}

(Submitted December 2018; Reviewed March 2019; Accepted April 2019)

\begin{abstract}
The ultimate goal of this study is to develop a model representing the in-plane behaviour of plasterboard ceiling diaphragms, as part of the efforts towards performance-based seismic engineering of low-rise light timber-framed (LTF) residential buildings in New Zealand (NZ).

LTF residential buildings in NZ are constructed according to a prescriptive standard - NZS 3604 Timberframed buildings [1]. With regards to seismic resisting systems, LTF buildings constructed to NZS3604 often have irregular bracing arrangements within a floor plan. A damage survey of LTF buildings after the Canterbury earthquake revealed that structural irregularity (irregular bracing arrangement within a plan) significantly exacerbated the earthquake damage to LTF buildings. When a building has irregular bracing arrangements, the building will have not only translational deflections but also a torsional response in earthquakes. How effectively the induced torsion can be resolved depends on the stiffness of the floors/roof diaphragms. Ceiling and floor diaphragms in LTF buildings in NZ have different construction details from the rest of the world and there appears to be no information available on timber diaphragms typical of NZ practice.

This paper presents experimental studies undertaken on plasterboard ceiling diaphragms as typical of NZ residential practice. Based on the test results, a mathematical model simulating the in-plane stiffness of plasterboard ceiling diaphragms was developed, and the developed model has a similar format to that of plasterboard bracing wall elements presented in an accompany paper by Liu [2]. With these two models, three-dimensional non-linear push-over studies of LTF buildings can be undertaken to calculate seismic performance of irregular LTF buildings.
\end{abstract}

\section{INTRODUCTION}

Construction of residential light timber-framed (LTF) buildings in New Zealand largely follows a prescriptive standard NZS3604 Timber-framed buildings [1]. The Canterbury earthquakes in 2011 provided a valuable test laboratory for studying seismic performance of LTF residential buildings and all LTF houses achieved the current New Zealand Building Code objective of life safety without collapse. However, earthquake damage to LTF buildings varied significantly, some had no damage at all while others were badly damaged and had to be demolished. Current seismic design requirements of LTF buildings bear no relations to the expected performance/damage of the buildings in a design earthquake event.

A damage survey of several hundred LTF buildings after the earthquake revealed that structural irregularity (irregular bracing arrangement within a plane) significantly exacerbated the earthquake damage to the buildings [3]. NZS3604 allows irregular seismic bracing arrangement within a floor plan but specifies irregularity limits. These irregularity limits were established based on engineering rule of thumb, rather than on a rigorous scientific basis $[4,5]$. Based on the lessons learnt from the earthquakes, there is a need to understand and quantify the effect of structural irregularity and adjust irregularity limits in current NZS 3604 if necessary.

Seismic performance of irregular structures is a very complicated subject. There are many uncertainties in predicting seismic performance of structures with irregular bracing arrangements, as concluded by the Canterbury Earthquake
Royal Commission Investigation [6]. The Commission was referring to commercial buildings, but this is equally true for LTF houses with irregular bracing arrangements. The irregularity causes the structure to have not only translational deflections but also a torsional response. How effectively the induced torsion can be restrained depends on the stiffness of the floors/roof diaphragms, because the diaphragms need to transfer the seismic actions from the lightly braced areas to the heavily braced areas. Floors/ceiling diaphragms in LTF buildings are constructed of timber frames sheathed with panel products, and they are neither rigid nor flexible. Adequate quantification of the in-plane stiffness of floors/ceiling diaphragms is essential to properly capture the seismic effects of the irregular bracing arrangement in an LTF building.

Overseas research on in-plane behaviour of timber floors and ceiling diaphragms revealed that the in-plane behaviour of these diaphragms is dependent on many factors including types of sheathing, sheathing-frame fixing details, aspect ratios of diaphragms, and other construction details. Carradine et al [7] tested seven full-scale floor diaphragms to study the effect of floor aspect ratios and fastener schedules on the in-plane stiffness. It was found that highest shear stiffness was attained when the diaphragms were loaded along the joist span direction. However, the highest global bending stiffness was attained when the diaphragms were loaded perpendicular to the joist span direction. Kirkham et al [8] experimentally studied the effects of roof pitch on in-plane behaviour of roof diaphragms. Ten full-size plywood roof diaphragms (gable roofs, hip roofs, and flat roofs) were constructed using metal plate connected (MPC) wood trusses or joists. The test results showed that roof

\footnotetext{
1 Corresponding Author, Senior Structural Engineer, BRANZ, Porirua, angela.liu@branz.co.nz (Member)

2 Lecturer, University of Canterbury, Christchurch, Minghao.li@catnterbury.ac.nz (Member)

3 Senior Structural Engineer, BRANZ, Porirua, roger.shelton@branz.co.nz
} 
pitch significantly affected the apparent stiffness of the gable roof, but not the strength; hip roofs had almost the same apparent stiffness and strength as the flat roofs. The apparent stiffness of the gable roofs were about $50 \%$ that of the flat roofs; and all the roofs exhibited approximately the same shear strength. Lucksiri et al. [9] studied the effect of irregular plan configurations on seismic performance of single-storey LTF houses by employing many surrogate building models in which the roof diaphragm was assumed to be rigid. It was concluded that irregular floor configurations induced eccentricity and caused some parts of the buildings to significantly exceed drift limit of 3\% for collapse prevention. The closest study to NZ timber diaphragms was done in Australia by Saifullah et al [10] where plasterboard sheathing was used. In their study, strength and stiffness of a typical ceiling system used in cold formed steel framed domestic structures was studied. Two experimental tests on ceiling diaphragms following typical Australia practice were conducted using two different test setups: a cantilever setup and a beam setup. It was found that the beam test setup gave greater strength and stiffness of the diaphragm than the cantilever setup; and unlike wood-based panel sheathing, plasterboard sheathing acted like a rigid body without visible relative movements between individual sheets.

In NZ, the construction techniques of roof ceiling diaphragms in LTF buildings are different from overseas practices. One main difference is the use of plasterboards, instead of woodbased structural panels such as plywood and oriented strand boards (OSB), as lining materials. Other differences include the fixing details between linings to timber frames or at the ceilingwall junctions, etc. Consequently, the in-plane behaviour of $\mathrm{NZ}$ roof ceiling diaphragms is expected to be different from that of their overseas counterparts. Therefore, there is a need to study the in-plane behaviour of the ceiling diaphragms following typical New Zealand practice.

This paper presents the results of static cyclic loading tests conducted on plasterboard ceiling diaphragms and the study focuses on the following aspects:

- To investigate the effects of the spacings of fasteners on the in-plane stiffness of ceiling diaphragms;

- To study the effects of common construction details at ceiling-wall junctions on the in-plane stiffness of ceiling diaphragms;

- To establish the upper and lower bounds of in-plane stiffness of plasterboard ceiling diaphragms; and

- To establish equivalent in-plane shear rigidity of plasterboard ceiling diaphragms to simplify seismic analysis of LTF buildings considering the effect of in-plane stiffness of diaphragms on building global responses.

\section{CURRENT CEILING/FLOOR DIAPHRAGM CONSTRUCTION PRACTICE IN NZ}

According to NZS3604 [1], there are structural and nonstructural ceiling diaphragms, depending on the application situations. Structural diaphragms are only required where the bracing lines in the storey below are spaced at more than 6 metres. Table 1 lists the requirements for the structural and nonstructural diaphragms and the main difference is the spacing of the fasteners.

There are two types of ceiling diaphragm construction techniques in NZS3604; traditional dwanged ceiling and battened ceiling [12]. The traditional dwanged ceilings are typically used with on-site roof construction and are mainly used now in alterations or additions to existing buildings. Ceiling joists are used to span between walls and are spaced to suit the spanning capability of the ceiling lining. Dwangs are installed between the joists. The lining is directly fixed to the joists and the dwangs. This type of construction was the norm when NZS3604 was originally published in 1978. Nowadays, battened ceilings are used in most of LTF construction where prefabricated MPC timber trusses are used as roof framing, irrespective of structural or non-structural diaphragms. A typical configuration of battened ceiling diaphragm is shown in Figure 1. Figure 2 shows two types of common ceiling diaphragm framing practices in NZ, recommended by Winstone Wallboards [13]. Timber or metal battens can be used and they are connected with the top plates of walls to provide adequate fixing of the ceiling lining at the ceiling-wall junctions. Battens are also attached to the bottom chords of the roof trusses. Plasterboard linings are then fixed to the battens and the top plates at the ceiling-wall junctions.

\section{Table 1: Provisions in NZS3604 for ceiling diaphragms.}

\begin{tabular}{|c|c|c|}
\hline Components & $\begin{array}{c}\text { Structural } \\
\text { diaphragms }\end{array}$ & $\begin{array}{c}\text { Non-structural } \\
\text { diaphragms }\end{array}$ \\
\hline $\begin{array}{l}\text { Spacing of } \\
\text { screws for } \\
\text { sheet fixing }\end{array}$ & $\begin{array}{l}150 \mathrm{~mm} \text { along sheet } \\
\text { edges, } 300 \mathrm{~mm} \\
\text { along intermediate } \\
\text { supports }\end{array}$ & $\begin{array}{l}200 \mathrm{~mm} \text { along sheet } \\
\text { edges, } 200 \mathrm{~mm} \text { along } \\
\text { intermediate supports }\end{array}$ \\
\hline
\end{tabular}

Frame details No specific details for either structural or nonstructural diaphragm

Sheet sizes Same for either structural or non-structural diaphragms

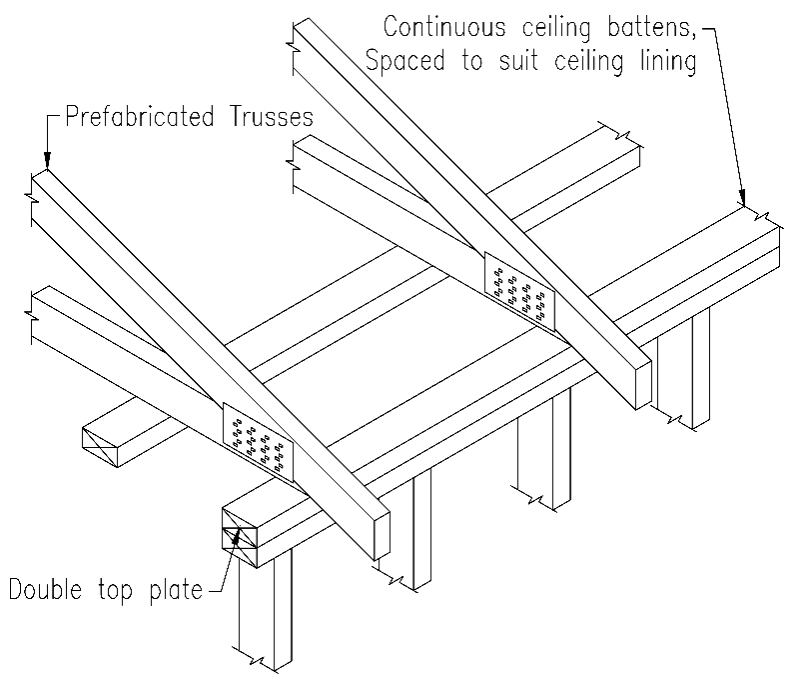

Figure 1: Configuration of battened ceiling [12].

\section{EXPERIMENTAL STUDIES}

This study only considers the battened ceiling diaphragms due to their dominant use in current LTF construction in NZ. The test programme consisted of two test stages: one full-scale ceiling diaphragm in the first stage and three small-scale ceiling diaphragms in the second stage. The full-scale ceiling diaphragm specimen represented a common plasterboard ceiling practice nowadays and it was tested by subjecting the ceiling diaphragm to in-plane static cyclic loading along the roof framing orientation. The objective of the full-scale test was to investigate the deformation mechanisms and establish benchmark of in-plane rigidity of a typical plasterboard ceiling diaphragm practice. For the small-scale ceiling diaphragm tests, one of the tests had identical edge construction details as the full-scale ceiling diaphragm specimen while the other two tests had different construction details, representing different practical applications. The objective of the small-scale tests was to quantify the effects of different construction details on inplane rigidity of ceiling diaphragms. 


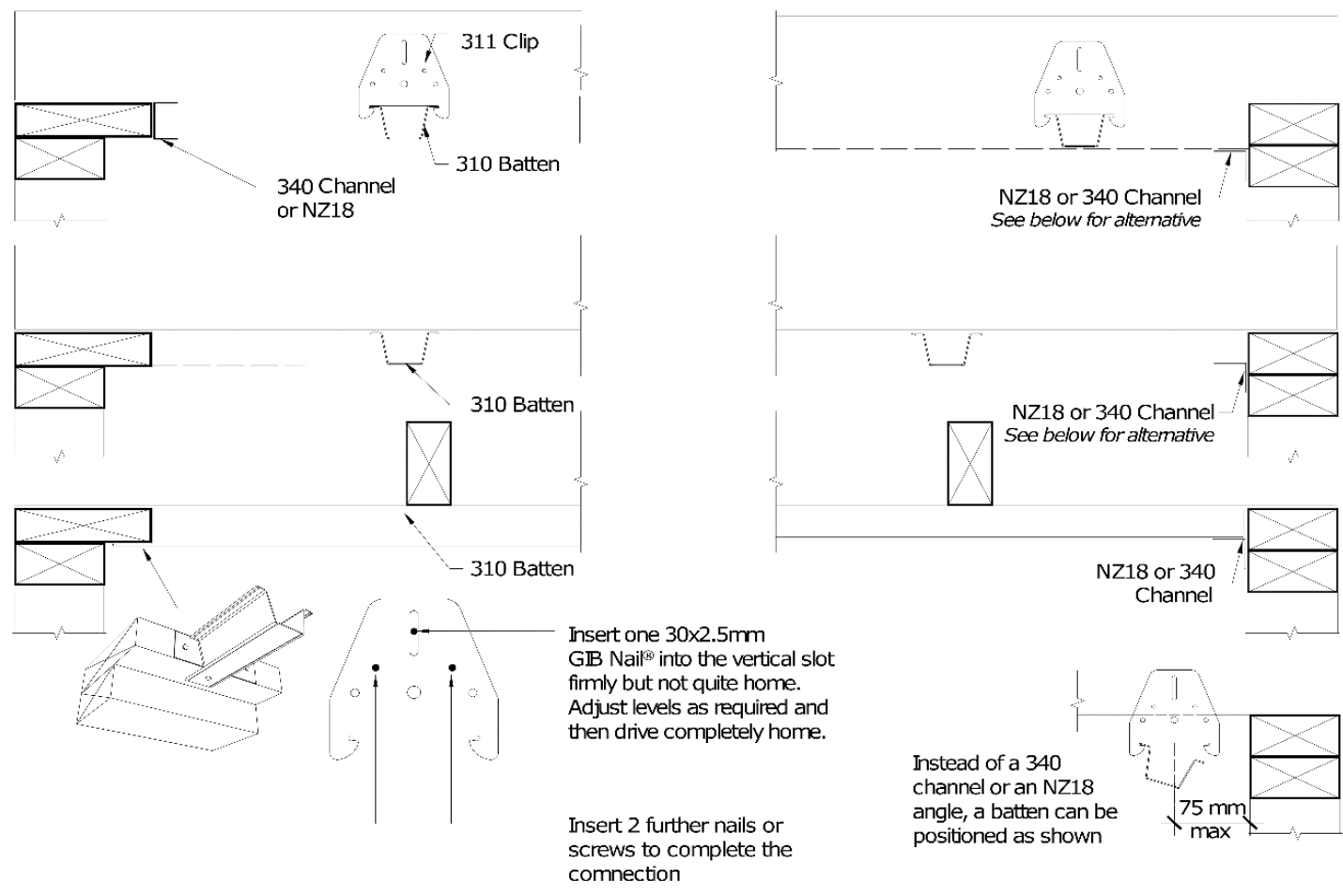

Figure 2: Common practice [13].

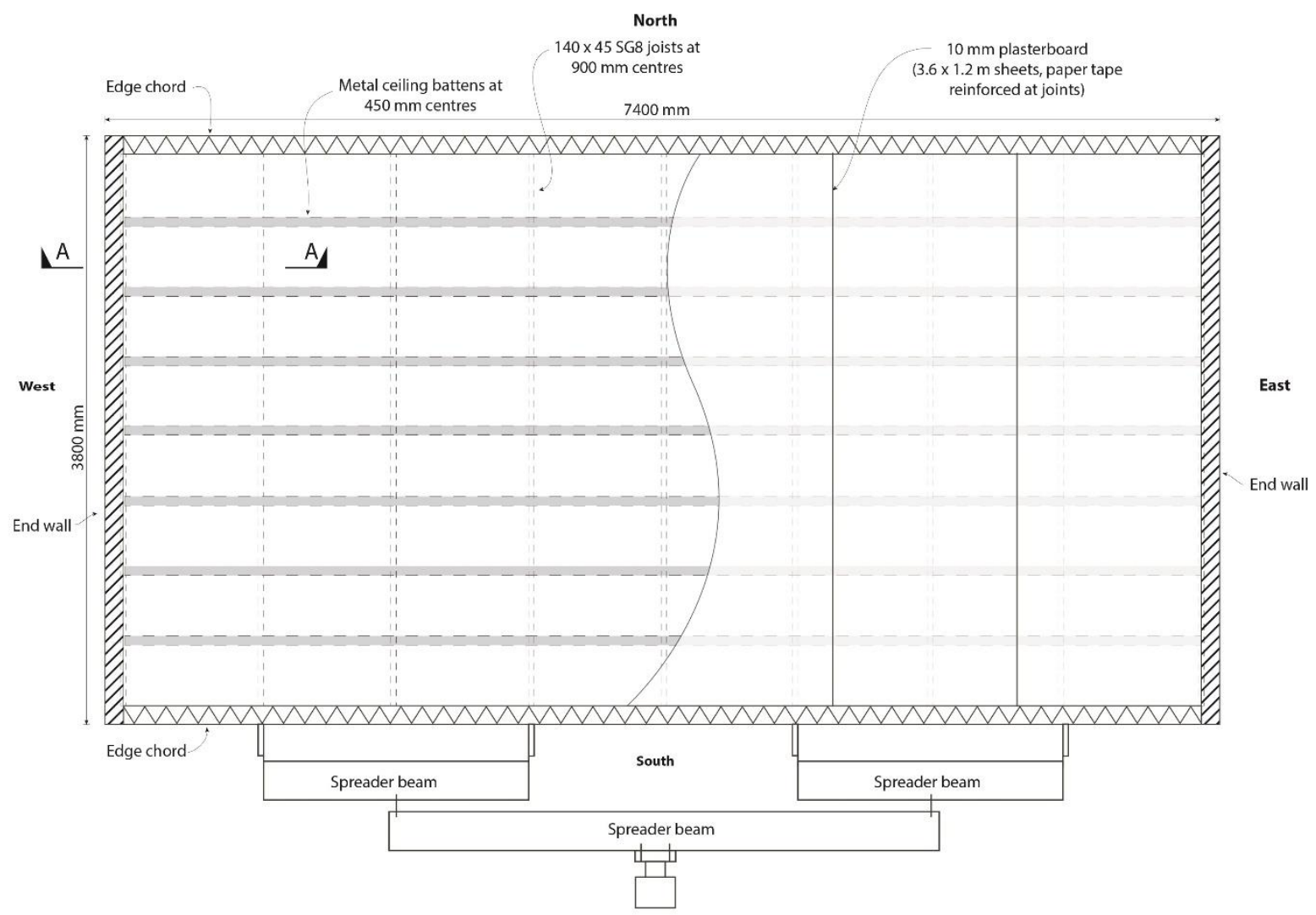

Figure 3: Plan of the full-scale ceiling test specimen. 


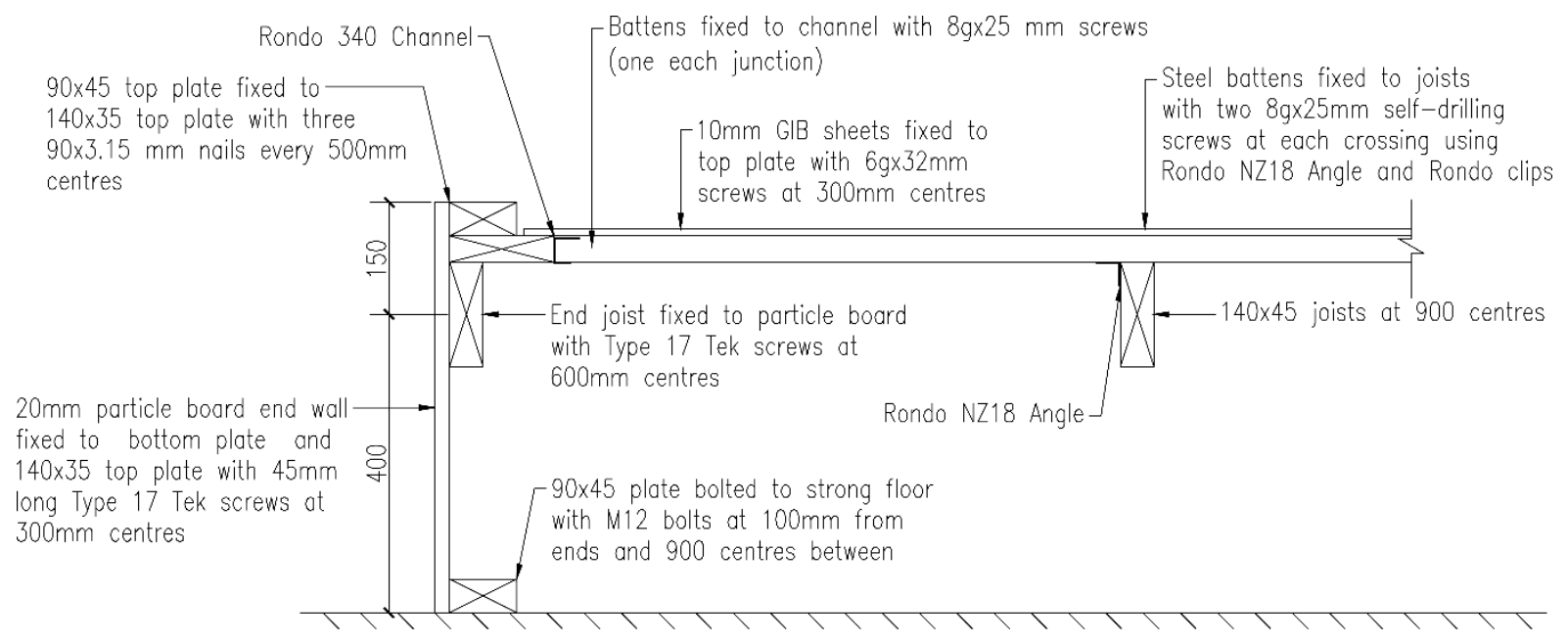

\section{Section A-A}

Figure 4: Edge details of the test specimen and the support details.

\section{The Full-scale Ceiling Diaphragm Test}

The test was designed to quantify the in-plane stiffness of a typical NZ plasterboard ceiling as noted above. For simplicity, a rectangular specimen was constructed, spanning between two end walls with the edge support walls forming the diaphragm chords. It was loaded by articulated strongbacks to simulate uniform loading along one edge.

\section{Specimen and Test Setup}

The plan size of the full-scale ceiling diaphragm specimen was $7.2 \mathrm{~m} \times 3.6 \mathrm{~m}$, constructed following one common battened ceiling diaphragm practice. The specimen was constructed upside down for easier viewing of the behaviour and it was believed that the performance would be the same as it was constructed the correct way up. Figure 3 shows the plan view of the full-scale ceiling diaphragm specimen. One cross section through the critical elements is illustrated in Figure 4.

All the framing members, except for battens, were SG8 kiln dried Radiata Pine. The joists, representing either joists or trusses in a real structure, were $140 \times 45$ SG8 members spaced at $900 \mathrm{~mm}$ centres. Each joist rested on two rollers to allow them to move in the plane of the diaphragm with minimal friction during testing (see Figure 5).

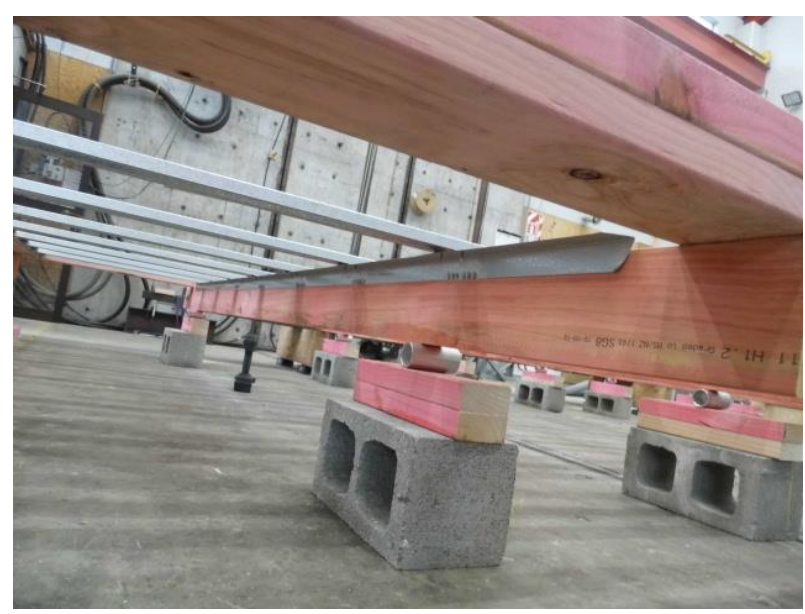

Figure 5: Underside of ceiling diaphragm specimen during construction showing joists, battens, Rondo N18 angles and supporting rollers.
Around the perimeter of the diaphragm, a $140 \times 35$ mm SG8 plate, simulating the top member of a double top plate as illustrated in Figure 2, was nailed to the joists with two $\varnothing 3.15 \times 90 \mathrm{~mm}$ nails at each joist crossing to simulate the skew nailed connection in normal practice. At the ends of the specimen, the joists were screwed directly to the particleboard transfer sheet with Type 17 Tek screws at $300 \mathrm{~mm}$ centres. At each corner of the diaphragm and at a butt joint on each of the two long sides, the $140 \times 35 \mathrm{~mm}$ plates were joined with a Mitek 6T10 Tylok toothed plate connector (see Figure 6).

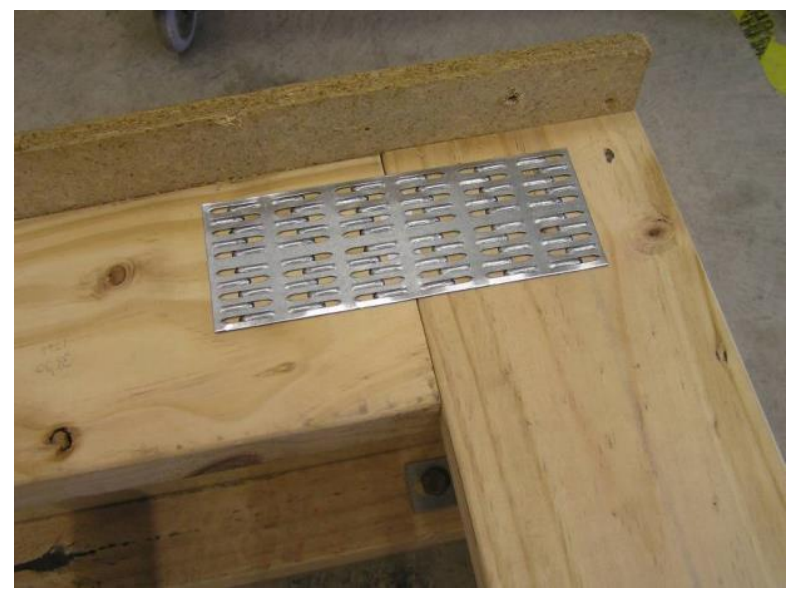

Figure 6: Mitek 6T10 Tylok connector at corner.

A $90 \times 45$ plate was fixed on top of the $140 \times 35$ plate. The $90 \times 45$ plate simulated the lower member of a twin top plate in normal construction and it was fixed to the $140 \times 35 \mathrm{~mm}$ plate with two $\varnothing 3.15 \times 90 \mathrm{~mm}$ nails at each joist crossing (i.e. $900 \mathrm{~mm}$ centres). At the ends of the specimen, the $90 \times 45$ plate was fixed to the $140 \times 35 \mathrm{~mm}$ plate using three $\varnothing 3.15 \times 90$ nails at $500 \mathrm{~mm}$ centres.

The battens were Rondo ceiling steel battens spaced at $450 \mathrm{~mm}$ centres and these battens were fixed to the joists with two $8 g \times 25$ mm self-drilling screws through the "brim" of the top hat at each joist crossing. These screws secured the battens to Rondo N18 Angles, which were fixed to the joists near the batten crossings using six $6 \mathrm{~g} \times 32 \mathrm{~mm}$ screws (see Figure 5)

Additionally, at each batten-joist crossing, a Rondo Clip was clipped to each batten and fixed to the joist using three $6 \mathrm{~g} \times 32$ $\mathrm{mm}$ screws, as shown in Figure 7. 


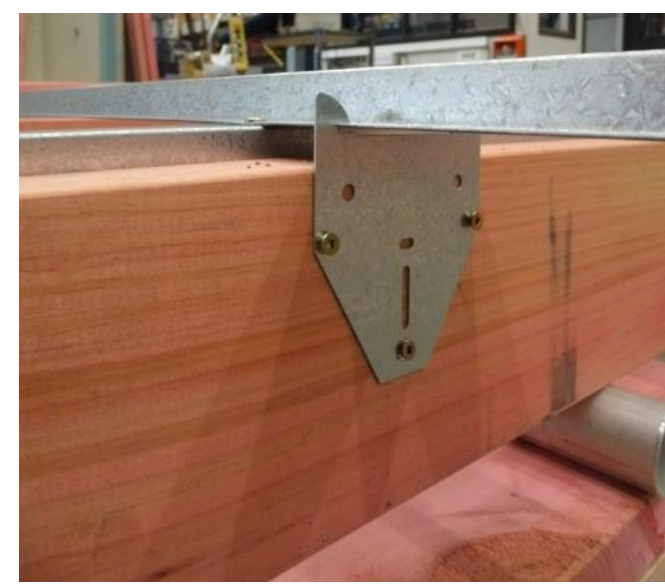

Figure 7: Batten-joist connection with a clip.

At the ends of the diaphragms, the ceiling battens were located in a Rondo 340 steel Channels and the channel section was fixed to the $140 \times 35 \mathrm{~mm}$ plate with $6 \mathrm{~g} \times 32 \mathrm{~mm}$ screws spaced at $300 \mathrm{~mm}$ centres. The ceiling battens were fixed to the channel section with a single $8 \mathrm{~g} \times 25 \mathrm{~mm}$ self-drilling screw at each batten end. Figure 8 shows the ceiling framing prior to lining.

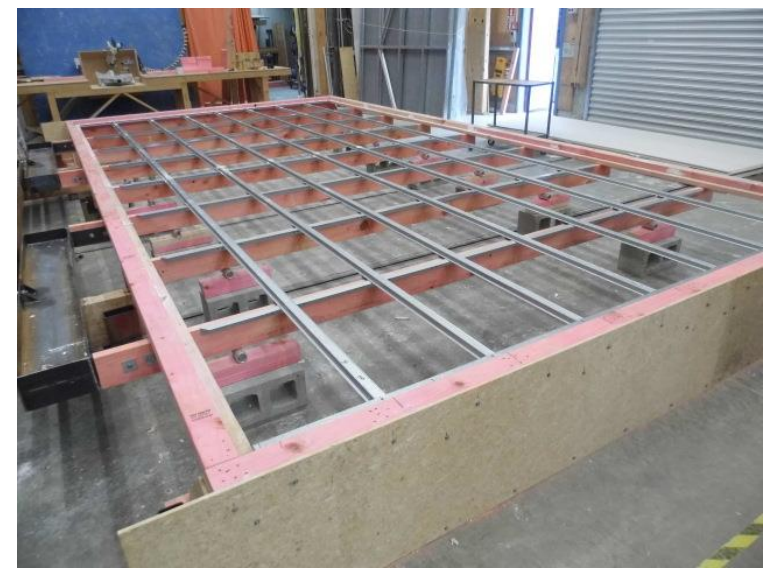

Figure 8: Framing of the full-scale ceiling test specimen.
Winstone GIB standard $10 \mathrm{~mm}$ thick plasterboard sheets of 3.6 $\mathrm{m} \times 1.2 \mathrm{~m}$ was fixed to the joists and perimeter framing, and paper tape reinforced and stopped at sheet joints. Sheet fixings were $6 \mathrm{~g}$ screws, spaced at $150 \mathrm{~mm}$ around the perimeter $(50$ $\mathrm{mm}$ and $100 \mathrm{~mm}$ from each corner), and $300 \mathrm{~mm}$ along the battens. Figure 9 shows the completed test specimen prior to the testing.

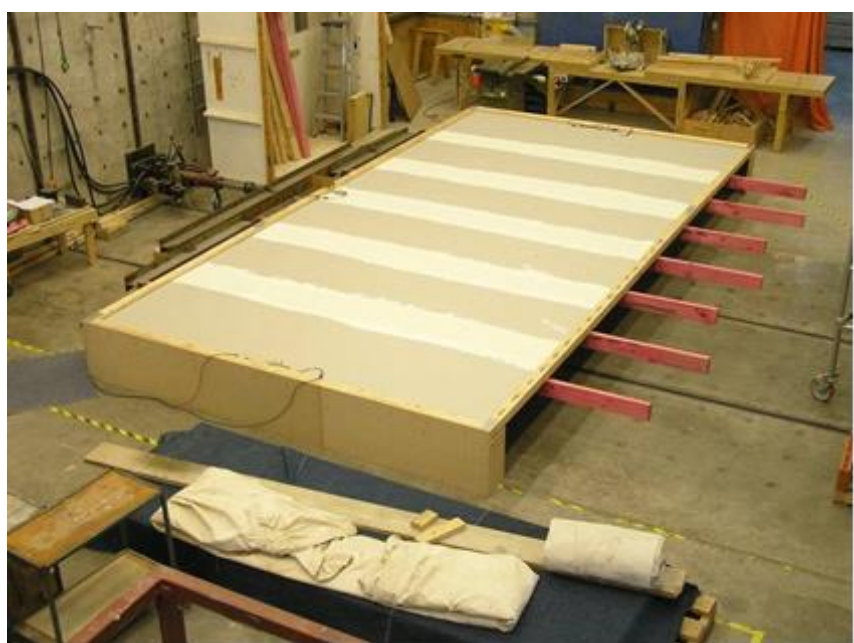

Figure 9: Full-scale test specimen prior to the test.

Instrumentation and Loading Protocol

Linear potentiometers were used to record screw slips (movements of the plasterboard relative to framing) and diaphragm displacements at various locations of the diaphragm. The arrangement of linear potentiometers for measuring screw slips is shown in Figure 10, and the arrangement of linear potentiometers for measuring the displacements of frame members relative to the floor is shown in Figure 11. Applied loads and ram displacements were also recorded.

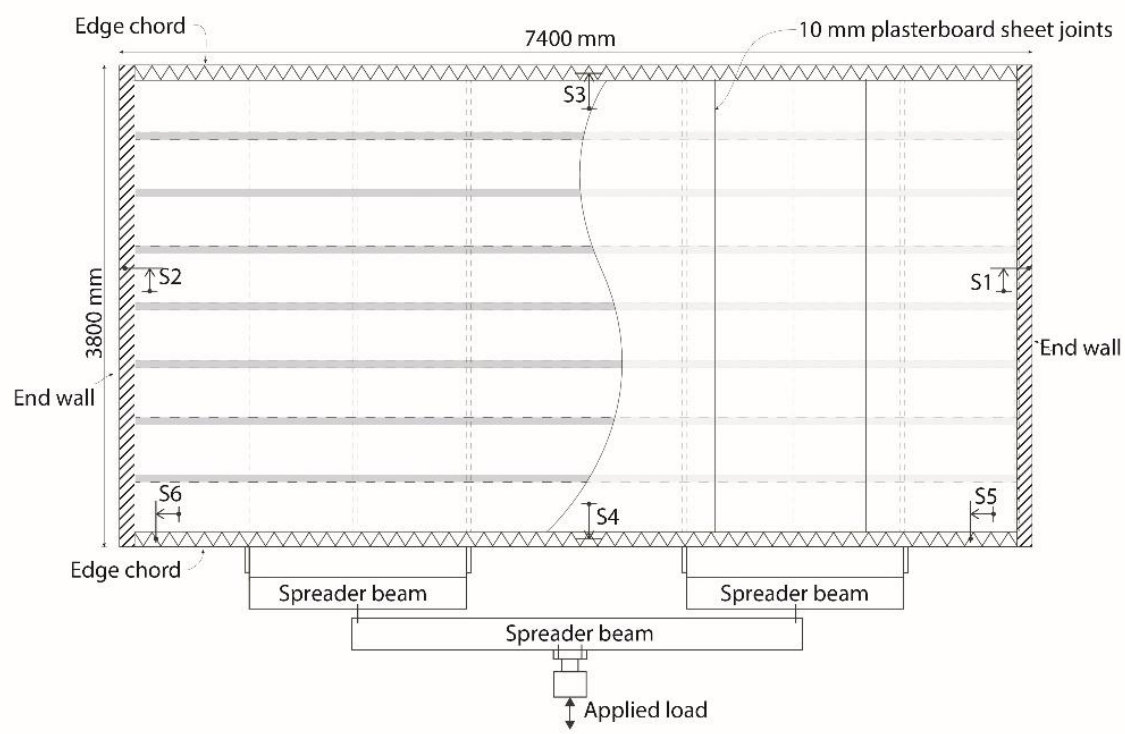

Figure 10: Arrangement of slip gauges. 


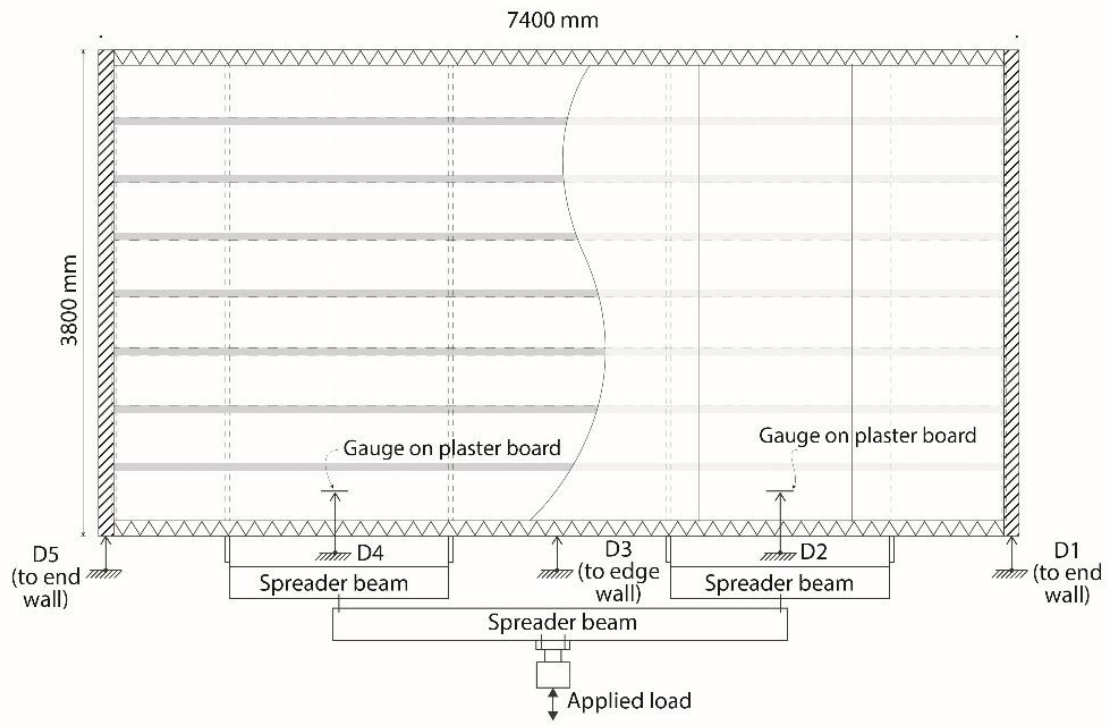

Figure 11: Arrangement of displacement gauges.

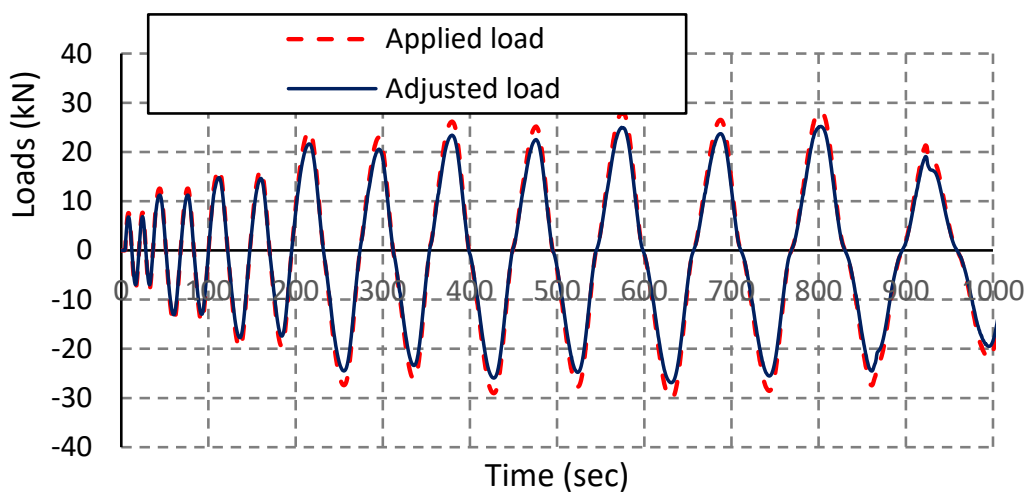

Figure 12: Plot of applied and adjusted loads.

The full-scale ceiling diaphragm was tested using a forcecontrolled quasi-static cyclic loading sequence. The in-plane loading was applied at four points along the long side of the diaphragm, via the ceiling joists, to simulate the in-plane seismic actions induced in the diaphragms. Two identical cycles were applied at each of the following load levels, $\pm 8 \mathrm{kN}, \pm 15$ $\mathrm{kN}, \pm 20 \mathrm{kN}, \pm 25 \mathrm{kN}, \pm 30 \mathrm{kN}, \pm 35 \mathrm{kN}, \pm 40 \mathrm{kN}$, and so on until the peak load was achieved. After the peak load was reached, the loading protocol was changed to be displacement controlled, also including two identical loading cycles at each of the following displacement levels, $5 \mathrm{~mm}, 6 \mathrm{~mm}, 8 \mathrm{~mm}$, and $10 \mathrm{~mm}$ until the final failure occurred. The applied loading regime is shown in Figure 12.

\section{Damage Observation}

Throughout the test, the plasterboard sheathing over the entire diaphragm moved as if it was a rigid body with no visible cracking or movement between the sheet joints. This was a different phenomenon from timber diaphragms with woodbased panel sheathing, such as, plywood. The damage was limited to the attachment fixings along the diaphragm edges. Figure 13 shows the overview of the diaphragm (a) as well as the highlighted damage areas at the end of the test (b, c and d).

During the early loading cycles, no visible movement was observed in any parts of the specimen. As the applied load increased, slip between plasterboard and framing cause the screw heads to bend over, resulting in "rotation" of the head in the paper sheet facing (Figure 13 (c)). As the loading reached about $15 \mathrm{kN}$, screw slip increased until the screws had formed "slots" in the plasterboard and eventually tore through the edges of the sheets (Figure 13 (d)). As the loading progressed, it was observed that the screws around the corners were significantly more stressed than the screws further away from the corners. This is commonly observed in racking tests on plasterboard sheathed bracing walls [14] and it was also reported by Sinha and Gupta [15]. Uneven load sharing between the fasteners or stress concentration to the screws around the corners is one of the characteristics observed of plasterboard sheathed structural elements (either walls or diaphragms). This causes the plasterboard sheathed elements to perform in a more brittle manner, in comparison with their counterparts with wood-based panel sheathing, resulting in pinched load-displacement behaviour.

Due to higher stress around the corners of the diaphragms, the corner attachments were damaged first. Failure modes included significant screw slip, screw head pull-through and edge tearing of the plasterboard sheets. As the loading cycles continued, the damage to the attachments progressed towards the centres of the diaphragm edges. As a result, the effectiveness of composite diaphragm actions, which utilise timber frames as chord members to provide flexural resistance and plasterboard sheathing as web member to resist shear, reduced significantly. This led to significant reduction of the diaphragm stiffness and strength. At the last few cycles of the loading, the plasterboard sheathing behaved as if it was completely detached at its edges from the framing. 


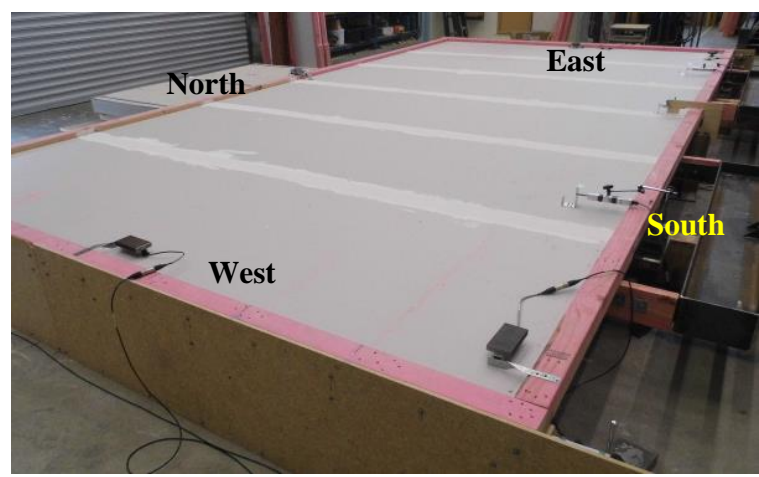

(a) Overview of test specimen (before loading)

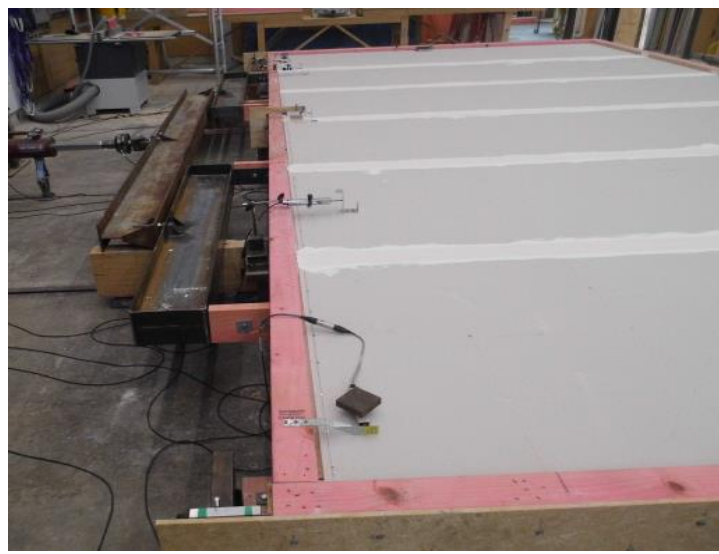

(b) Closeup (no cracking along sheet joints)

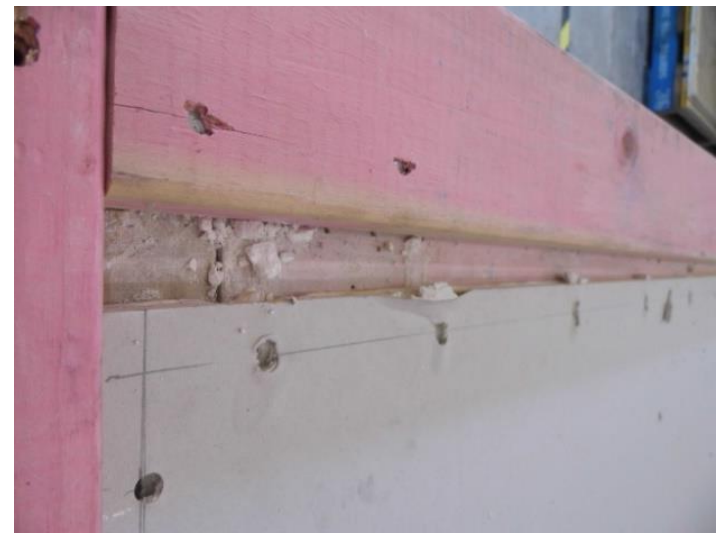

(c) Screw head rotating due to slip between sheets and framing

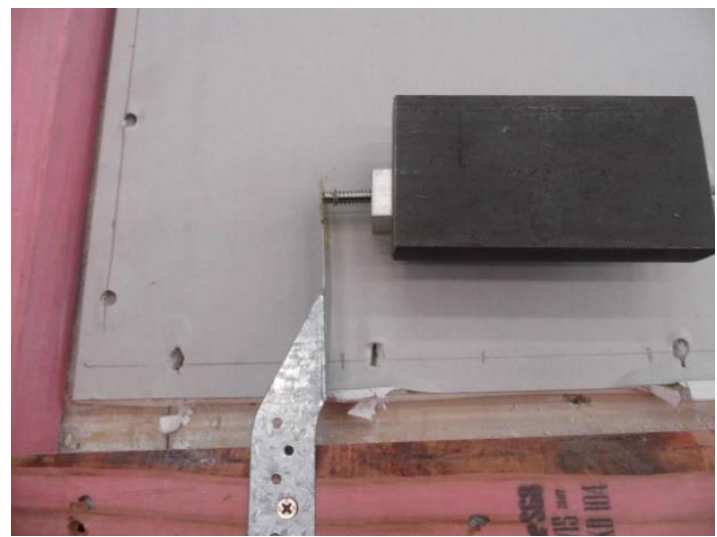

(d) Complete detachment of sheets, showing slotting and head pull through)

Figure 13: Diaphragm during the test.
Load-Displacement Responses

Figure 14 shows the load-deflection hysteresis loops, where the deflection refers to the relative deflection at the mid-span of the test specimen to the supports (namely, the deflection associated with the supports has been removed). As shown in Figure 14, the plasterboard ceiling diaphragm performed in a relatively brittle manner. Stiffness degradation with the progress of loading was very significant, after the peak load was reached.

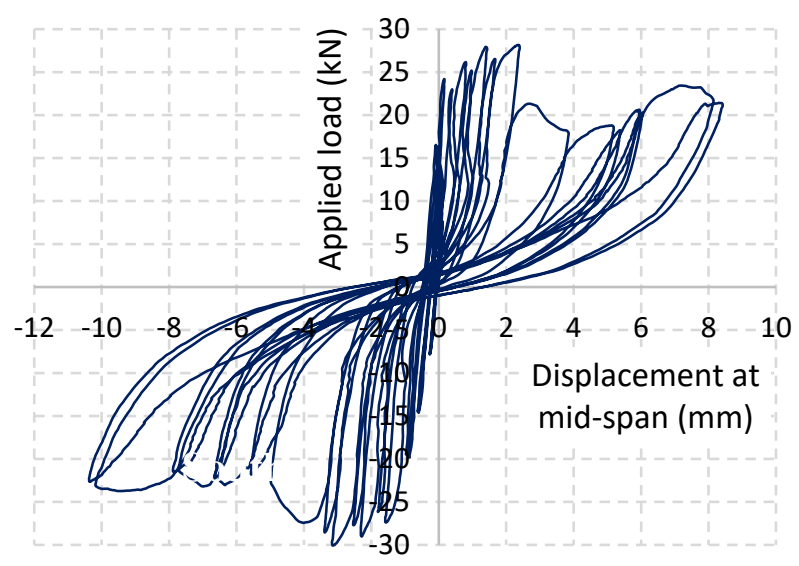

Figure 14: Load-deflection plots obtained from the full-scale ceiling diaphragm test.

Figure 15 shows the measured absolute deflections of the plasterboard lining at different locations. Clearly the plasterboard movements at different locations had negligible differences, meaning the sheathing almost moved as a relatively rigid plate.

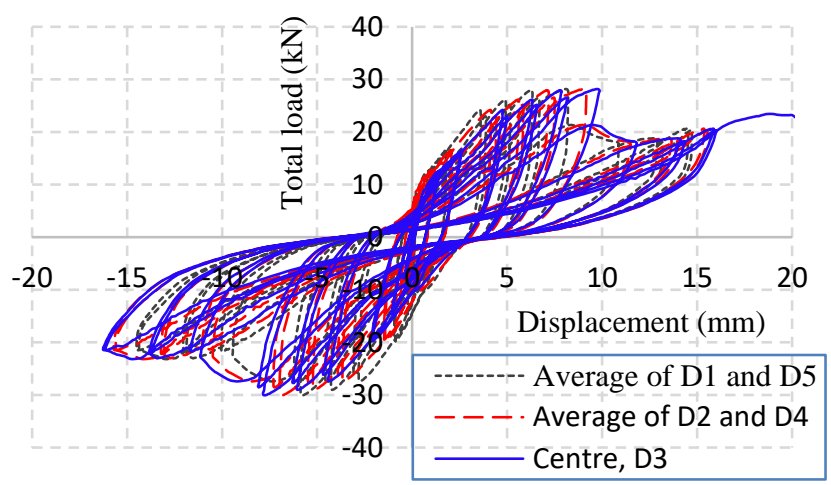

Figure 15: Absolute deflections at different locations of plasterboard sheathing ( $\mathrm{mm}$ ).

Figure 16 shows the screw slips (the average slips measured by slip gauges "S1 and S2" in Figure 10) versus the total diaphragm deflection measured over the loading sequence. It is obvious that the contribution of screw slips to the total deflection increased as the loading progressed, and it reached about $85 \%$ of total deflection. Clearly, the primary deformation source of the floor diaphragm was the movements associated with the attachment fasteners. 


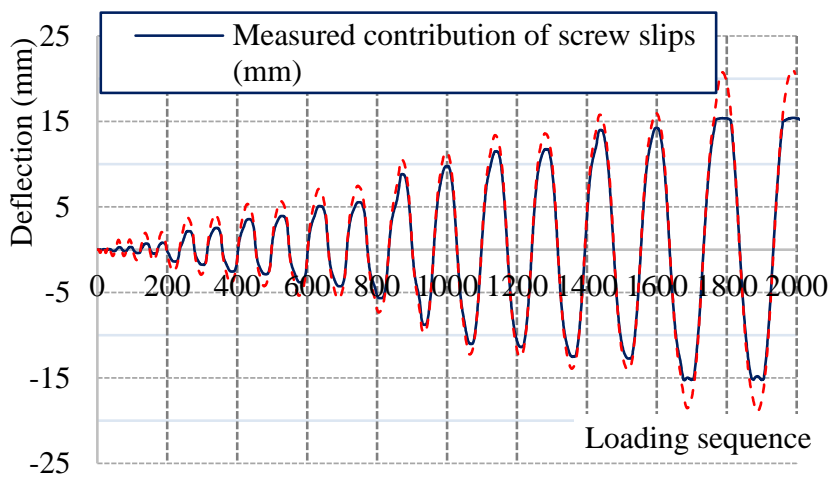

Figure 16: Screw slips versus the total deflection.

\section{Validation of NZS3603 Method [16]}

The experimental results obtained from the full-scale plasterboard ceiling diaphragm test were used to validate the application of the calculation method prescribed in NZS3603 to the case of plasterboard ceiling diaphragms. Timber diaphragms are conventionally treated as simply supported deep beams and are analysed using the deep beam analogy where the sheathing is the web of the beam and the top plates of the supporting walls or a continuous joist is the flange. NZS3603 gives a calculation method for estimating different deflection components for timber diaphragms sheathed by wood-based panels, such as plywood sheets. According to NZS3603, the total deflection of a timber diaphragm sheathed by plywood sheets is estimated as follows:

$\Delta_{\text {total }}=\Delta_{\text {flexural }}+\Delta_{\text {shear }}+\Delta_{\text {slip }}$

where:

$\Delta_{\text {flexural }}=5 \mathrm{PL}^{3} /\left(192 \mathrm{EAB}^{2}\right)$ and it is the deflection contribution due to in-plane bending deformation of the diaphragm. The primary contribution of a timber diaphragm to bending rigidity is attributed to the "chords" of the diaphragm. $\mathrm{P}$ is the applied load, $\mathrm{L}$ is the span of the diaphragm, A is the sectional area of one chord, $\mathrm{B}$ is the distance between diaphragm chord members, and $\mathrm{E}$ is the elastic modulus of the chords.

$\Delta_{\text {shear }}=\mathrm{PL} /(8 \mathrm{GBt})$ and it is the deflection contribution due to shear deformation where the shear resistance is primarily provided by the "web" of the diaphragm; $t$ is the thickness of the web (the sheathing in this case) and G is the shear modulus of the web; and

$\Delta_{\text {slip }}$ is the contribution of the screw slips.

In the validation of the NZS3603 method, $\mathrm{E}=8,000 \mathrm{MPa}$ was used for SG8 timber, G $=700 \mathrm{MPa}$ was used as the shear modulus of plasterboard linings as reported by Thurston [14] For the slip component, $\Delta_{\text {slip }}$, the screw slip model as in Figure 17(a) was used and this screw slip model was derived from slip tests of simple two screw-plasterboard-timber frame components as shown in Figure 17(b) (from a set of unpublished test data at BRANZ). According to NZS3603, the slip contribution to the total diaphragm deflection is determined, based on nail slip, aspect ratio of the sheets and number of the sheets. For plasterboard ceiling diaphragm, slip contribution can be directly taken as the screw slip, which was derived from the screw slip model based on average load on each screw.

The estimated total mid-span deflections of the tested full-scale diaphragm at the peak loads were obtained, using the slip model for the 4th cycle as illustrated in Figure 17(a) and Equation (1). The estimated mid-span deflections were then compared with the measured total deflection at the mid-span, as shown in Figure 18. It was found that the differences between the estimated deflections and the measured deflections generally reduced as the loading progressed. This is because, as the loading progresses, the applied loads are more evenly spread among the screws and also the screw slip performance is closer to the slip model at 4 th cycle.

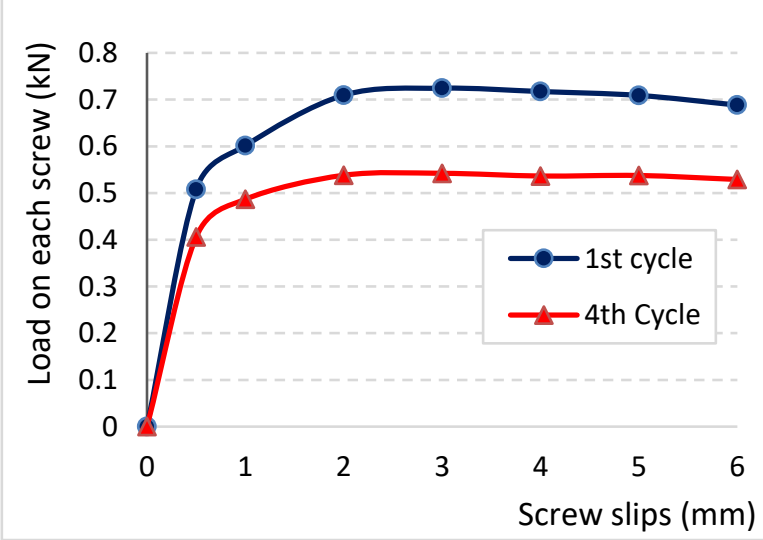

(a) Screw slip model

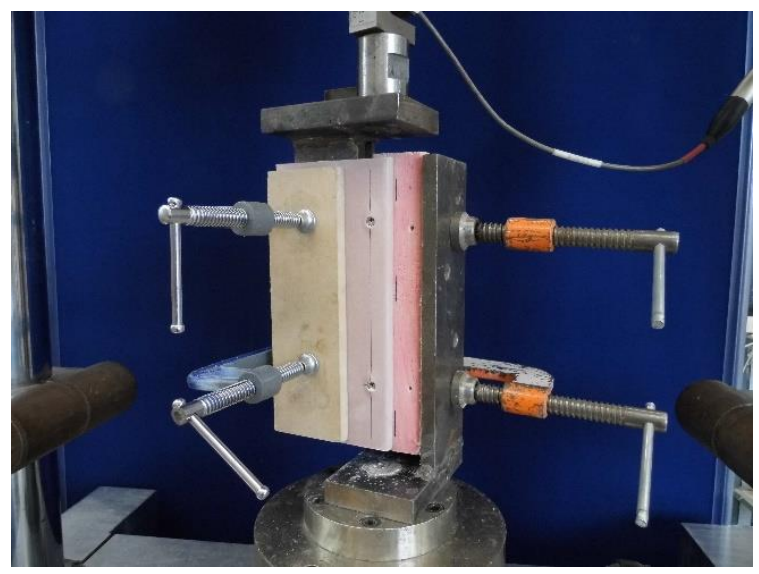

(b) Screw slip tests

Figure 17: Screw slip model.

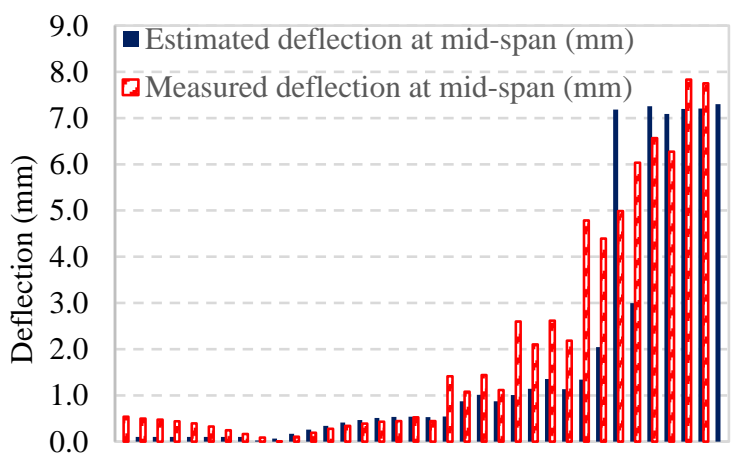

Test sequence

\section{Figure 18: Validation of predicted deflection versus measured deflection.}

Summary

The experimental study on the full-scale plasterboard ceiling diaphragm had the two main findings:

(1) The dominant contribution to the in-plane stiffness of plasterboard ceiling diaphragms was due to screw slips between plasterboard linings and the framing; and

(2) The deep beam analogy method in NZS 3603, although developed mainly for floors/roof diaphragms with wood-based panel sheathing, could be used for the plasterboard ceiling 
diaphragm, provided that the screw slip model is reasonably accurate.

\section{Small-Scale Ceiling Diaphragm Tests}

\section{Test Specimens and Setup}

The three small-scale specimens had a plan size of $1.2 \mathrm{~m} \times 1.2 \mathrm{~m}$ and the specimens were supported by light timber framed walls and braced in both directions. These three specimens were identical except for the different attachment details at the diaphragm edges, representing various types of ceiling construction details in practice. For all the specimens, the joists were $90 \times 45$ SG8 timbers spaced $600 \mathrm{~mm}$ and fixed to the top plates of the walls with two $\varnothing 3.15 \times 90$ nails at each end. This was exactly the same as used in the full-scale diaphragm test. Battens were $35 \mathrm{~mm}$ Rondo ceiling battens spaced at $450 \mathrm{~mm}$ and fixed to the joists using two $8 \mathrm{~g} \times 25 \mathrm{~mm}$ self-drilling screws, also the same as used in the full-scale test. Figure 19 shows the plan view of the test specimen and the schematic of the test setup.
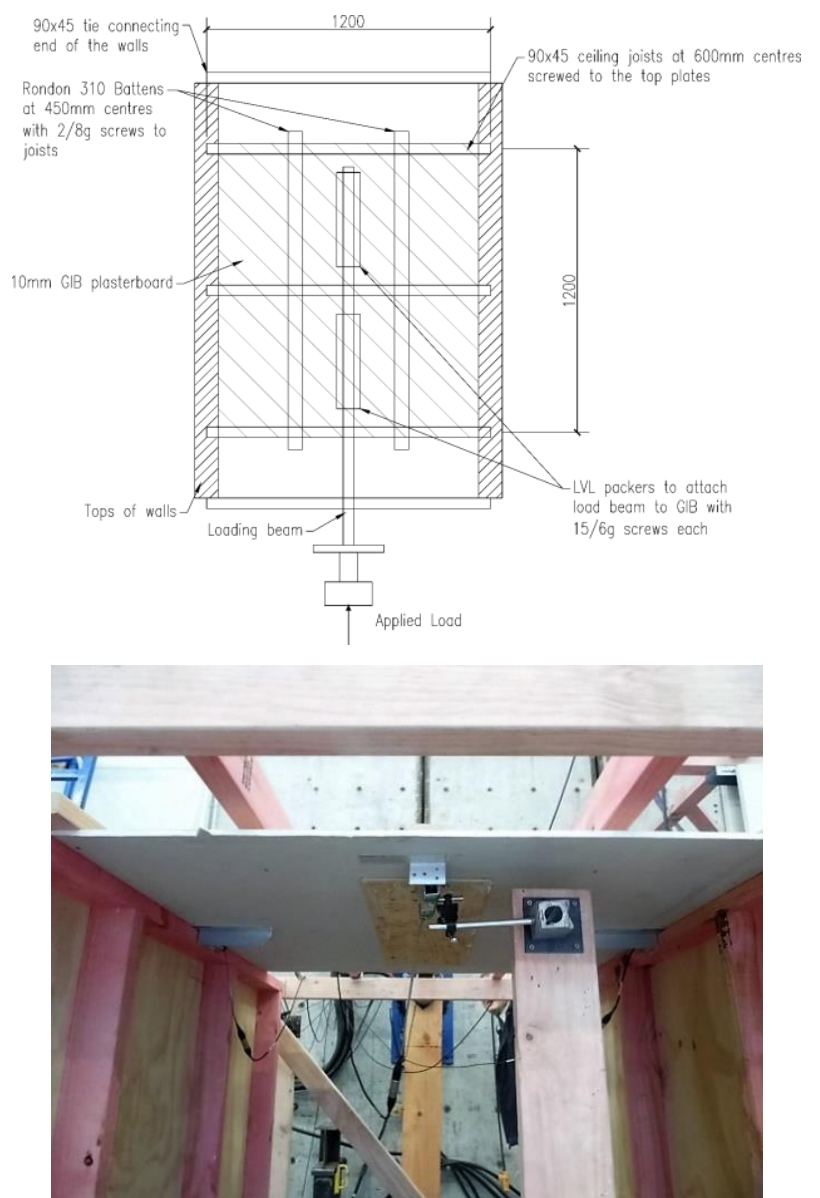

Figure 19: Plan and schematic views of small-scale ceiling diaphragm tests.
Table 2 summarises the details of small ceiling diaphragm specimens. Test A was designed to replicate the construction details of a segment of the full-scale diaphragm and was the benchmark test to study the effects of various construction details on in-plane stiffness of the ceiling diaphragms. Test B was identical to test A except that test B had tape-reinforced jointing details at the ceiling-wall junctions. Test $\mathrm{C}$ was also identical to test A except that the additional top plate was $90 \times 45$ SG8 timber with a NZ18 angle and screw fixings were spaced at $600 \mathrm{~mm}$, rather than $150 \mathrm{~mm}$.

\section{Instrumentation, Loading Protocol and Test Observations}

As shown in Figure 20, linear potentiometers were arranged to measure the absolute deflection at the top of the walls, absolute deflection at the centre of the diaphragm, screw slips between ceiling plasterboard sheets and the wall frames at both sides of the ceiling diaphragm. The loading schedule was displacementcontrolled. Two cycles of loading were applied at each of the displacement levels: $\pm 4 \mathrm{~mm}, \pm 8 \mathrm{~mm}, \pm 10 \mathrm{~mm}, \pm 12 \mathrm{~mm}, \pm 14$ $\mathrm{mm}, \pm 16 \mathrm{~mm}, \pm 18 \mathrm{~mm}, \pm 22 \mathrm{~mm}, \ldots$, or until failure occurred.

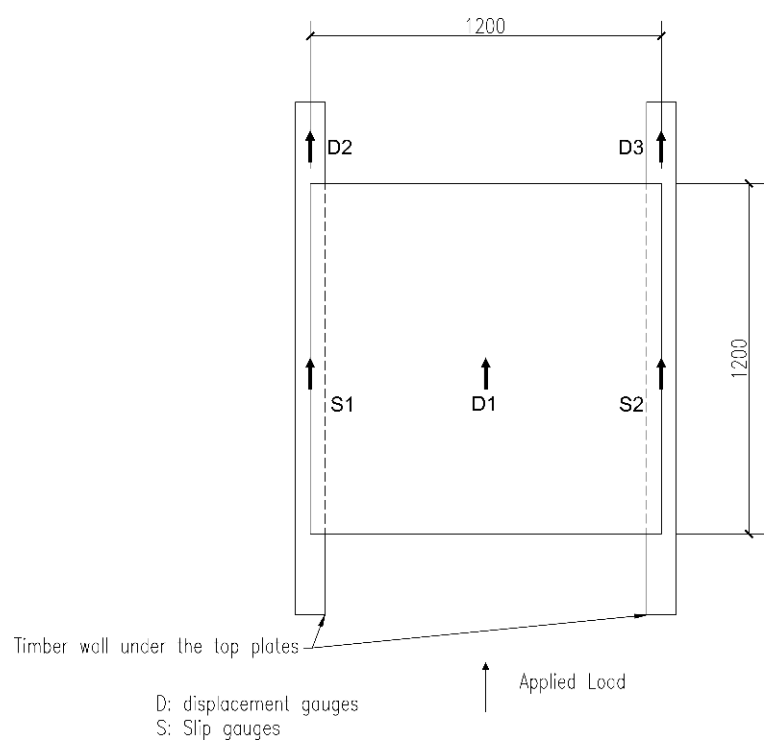

Figure 20: Instrumentation setup for the small-scale ceiling diaphragm specimens.

For the small-scale specimens, it was observed that the plasterboard sheathing behaved in a similar way to a monolithic rigid plate. Figure 21 shows the slip induced deflections versus the total deflections at mid-span of the ceiling diaphragms, where the mid-span deflections were the relative deflection of the ceiling diaphragm to the walls. It is apparent that most of the deformation occurred due to slip of the screws along the two sides of the diaphragms parallel to the loading direction. Figure 22 shows the hysteresis loops in terms of the applied load versus mid-span ceiling deformation for the ceiling diaphragm tests, where the mid-span ceiling deformation is derived from the measurements of displacements gauges, D1, D2 and D3.

Table 2: Small-scale ceiling diaphragms.

\begin{tabular}{cccccc} 
Test ID & $\begin{array}{c}\text { Additional plate on } \\
\text { top of wall top plate }\end{array}$ & Battens type & $\begin{array}{c}\text { Plasterboard } \\
\text { fixing at edge }\end{array}$ & $\begin{array}{c}\text { Edge reinforcing } \\
\text { (tape \& Stopped) }\end{array}$ & $\begin{array}{c}\text { Structural ceiling } \\
\text { diaphragm or not }\end{array}$ \\
\hline A & $140 \times 35$ & Steel & $\begin{array}{c}6 \mathrm{~g} \text { screws at a } \\
\text { spacing of } 150 \mathrm{~mm} \\
6 \mathrm{~g} \text { screws at a } \\
\text { spacing of } 150 \mathrm{~mm} \\
6 \mathrm{~g} \text { screws at a } \\
\text { spacing of } 150 \mathrm{~mm}\end{array}$ & No & Yes \\
B & $140 \times 35$ & Steel & Steel & Yes & No \\
C & $90 \times 45$ & &
\end{tabular}



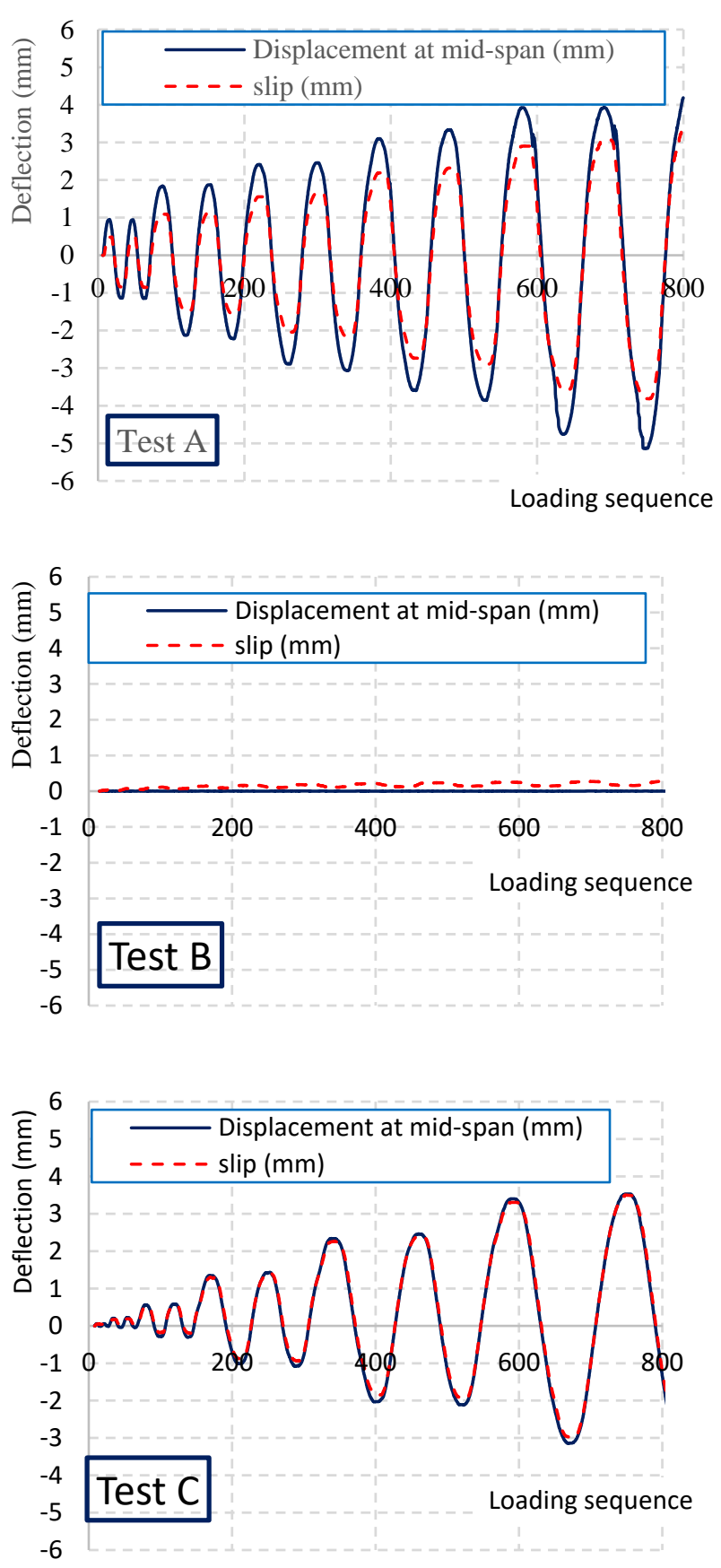

Figure 21: Contribution of screw slips versus the total deflections.

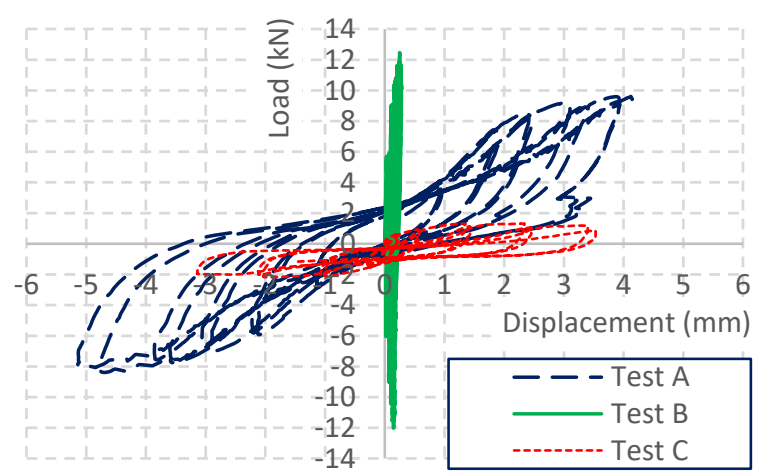

Figure 22: Hysteresis loops of load-deflection of small-scale ceiling diaphragms.

\section{Relative Stiffness of Ceiling Diaphragms}

The in-plane stiffness of plasterboard ceiling diaphragms is mainly attributed to screw slips. Thus, the stiffness of the screwed fixings can be used as an approximate indicator of estimating the diaphragm stiffness. Figure 23 illustrates the hysteresis loops of measured screw slips versus the applied loads for all three small-scale ceiling diaphragms, where the screw slips are the average of the measured slips from slip gauges S1 and S2 as shown in Figure 20. It can be seen that the highest in-plane rigidity was achieved when the ceiling-wall junctions were tape reinforced in test $\mathrm{B}$. In comparison, the lowest in-plane rigidity was observed in test $\mathrm{C}$ where the fixing spacing was quadrupled and the ceiling-wall junctions were not tape reinforced. The in-plane rigidity of the diaphragm in test A which had the same details as the full-scale test was in the middle range. It was also found that in test $\mathrm{B}$, although the tape reinforced joints between the ceilings and the walls enhanced the in-plane stiffness significantly, the stiffness degradation was abrupt after the joint failure was initiated.

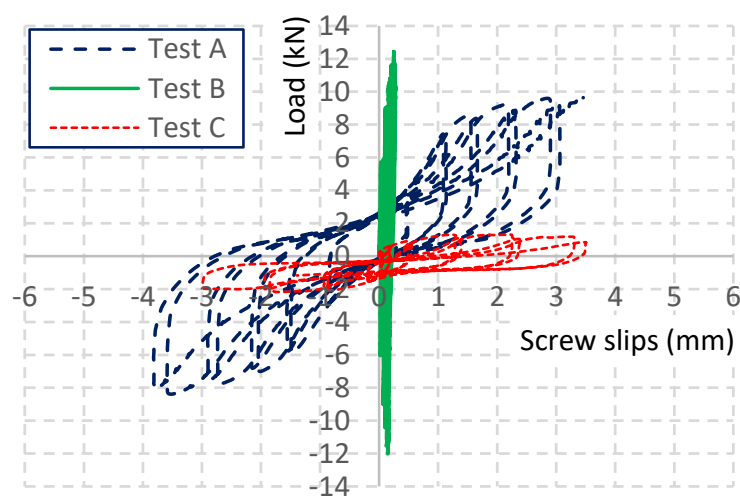

Figure 23: Hysteresis loops of load - screw slips of smallscale ceiling diaphragms.

Relative in-plane rigidity of the ceiling diaphragms was estimated for all the small-scale ceiling diaphragms. It was calculated as follows:

$\mathrm{R}_{\mathrm{k}}=(\mathrm{P} / \Delta) /\left(\mathrm{P}_{\mathrm{A}} / \Delta_{\mathrm{A}}\right)$

where:

$\mathrm{R}_{\mathrm{k}}=$ relative rigidity parameters

$\mathrm{P}=$ the average maximum load (average loads of positive loading cycle and negative loading cycle) applied to the specimen

$\Delta=$ the measured maximum slip (average slip values along the two sides of the ceiling parallel to the loading direction where the slips are the relative movement between ceiling and the wall top),

$\mathrm{P}_{\mathrm{A}}=$ the average maximum load (average loads of positive loading cycle and negative loading cycle) applied to test " $\mathrm{A}$ ", and

$\Delta_{\mathrm{A}}=$ the measured maximum slip for test "A" (average slip values along the two sides of the ceiling parallel to the loading direction where the slips are the relative movement between ceiling and the wall top),

The estimated relative in-plane rigidity of ceiling diaphragms with different edge details are summarised in Table 3 . From Table 3, it is evident that the reinforced tape jointing details enhanced the ceiling diaphragm's rigidity much more significantly than the batten orientation. The spacing of screw fixings from the plasterboard to framing was found to be a dominant factor of ceiling diaphragm rigidity, as revealed by comparing test A with test $\mathrm{C}$. 
It is noted that the spacing of screw fixings from plasterboard to framing was respectively $600 \mathrm{~mm}$ and $150 \mathrm{~mm}$ for test $A$ and test C. It is interesting that the increase of the screw fixing spacing is approximately proportional to the ceiling diaphragm flexibility, confirming that screw slip is the major contributor to the flexibility of plasterboard ceiling diaphragm.

Table 3: Relative ceiling diaphragm rigidity parameters.

\begin{tabular}{cc} 
Test ID & $\mathbf{R}_{\mathrm{k}}$ \\
\hline A & 1.0 \\
B & 17.0 \\
C & 0.22 \\
\hline
\end{tabular}

\section{A SIMPLIFIED METHOD TO ESTIMATE IN-PLANE STIFFNESS OF PLASTERBOARD CEILING DIAPHRAGMS}

Several researchers have attempted to develop methods to model the in-plane stiffness of ceiling/floor diaphragms. The models developed are mainly in two categories, finite element models and mathematical models involving engineering formulae.

Finite element models used for timber diaphragms model the engineering behaviour of each building component within a diaphragm (fasteners, frame members, sheathing, so on). An example of finite element models developed so far is the work by Saifullah et al [17]. Saifullah et al studied the stiffness of plasterboard ceiling diaphragms in light steel-framed residential structures. In this study, the finite element model of a plasterboard ceiling diaphragm was developed using ANSYS software. Non-linear deformation sources were the slips of screws from plasterboards to framing and the load-slip models of the screws used in finite element models were obtained based on shear connection tests conducted at component level.

In comparison, mathematical models are often developed based on an analogical theory. For timber diaphragms, a common mathematical model is the deep beam analogy. A representative of mathematical models based on the deep beam analogy is the method in NZS3603, which was originally developed by Dowrick and Smith [18] for timber diaphragms with woodbased sheathing. There are also a few mathematical models developed based on shear field analogy. Examples of mathematical models developed based on shear field analogy include the truss method developed by Kamiya [19] and the equivalent truss method developed by Moroder [20]. However, all these models were developed mainly for timber diaphragms sheathed by wood-based panels, such as plywood sheets.

No significant efforts have been made in estimating in-plane stiffness of timber-framed plasterboard ceiling diaphragms used in NZ residential construction. In this study, a closed form mathematical model, similar to the model developed for LTF plasterboard walls, is developed, based on the tests results, to represent the in-plane rigidity of plasterboard ceiling diaphragms.

To this end, the deformation mechanism analyses of plasterboard ceiling diaphragms are undertaken to help inform the model development. In detail, the method in NZS3603 is used for calculating the deflections of plasterboard ceiling diaphragms, and the shear deformation component and slip deformation component are summed as a combined deformation.
The total in-plane deformation of ceiling diaphragms is therefore expressed as:

$\Delta_{\text {total }}=\Delta_{\text {flexural }}+\Delta_{\mathrm{ss}}$

Where: $\Delta_{\text {flexural }}$ is the deflection contribution due to in-plane bending deformation and it is insignificant as described previously. $\Delta_{\text {flexural }}$ is calculated according to equation (1).

$\Delta_{\mathrm{ss}}$ is the combined deflection contribution due to screw slips and in-plane shear deformation, and it is the major contribution to the diaphragm's flexibility.

The combined slip-shear deformation component is calculated using the following equation:

$\Delta_{\mathrm{ss}}=\mathrm{PL} /\left(8 \mathrm{G}_{\mathrm{e}} \mathrm{Bt} \mathrm{e}_{\mathrm{e}}\right)$

Where: $t_{e}$ is the effective thickness of the plasterboard ceiling diaphragm and it is taken as the thickness of the plasterboard sheets; and $\mathrm{G}_{\mathrm{e}}$ is the equivalent shear modulus of the diaphragms which combines the effects of shear deformation within the plasterboard and the slip deformation of screw fixings.

Equivalent shear moduli at different loading peaks are derived using equations 3 to 4 , based on the test results obtained from the full-scale ceiling diaphragm test. The calibrated equivalent shear moduli are listed in Table 4 . It can be seen that $\mathrm{G}_{\mathrm{e}}$ degrades as the deflection increases, leading to non-linear performance of the ceiling diaphragms, as revealed from the full-scale diaphragm test.

Table 4: Equivalent shear moduli, $G_{e}$, of the full-scale ceiling diaphragm test.

\begin{tabular}{ccc}
$\mathbf{V}(\mathbf{k N} / \mathbf{m})$ & $\boldsymbol{\Delta}(\mathbf{m m})$ & $\mathbf{G}_{\mathbf{e}}(\mathbf{M P a})$ \\
\hline 1.1 & 0.5 & 450 \\
1.9 & 1 & 370 \\
2.5 & 1.6 & 300 \\
3.6 & 2.75 & 220 \\
3.6 & 4.5 & 160 \\
3.6 & 5 & 140 \\
4.0 & 6 & 110
\end{tabular}

Note: $V$ is the shear action in the two sides of the diaphragm, parallel to the loading direction; $\Delta$ is the translational deflection at mid-span of the diaphragm relative to the support

Based on the relative in-plane rigidity parameters in Table 3, the equivalent shear moduli of plasterboard ceiling diaphragms with different fixing details were estimated. Table 5 lists the estimated equivalent shear moduli for the ceiling diaphragms with different fixing details. Details of test B produce the highest in-plane rigidity while details of test $\mathrm{C}$ produce the lowest in-plane rigidity.

The equivalent shear moduli in Table 5 are only applicable to the typical NZ residential construction practice where roof joists/trusses are spaced at $900 \mathrm{~mm}$ centre to centre and $6 \mathrm{gx} 32$ $\mathrm{mm}$ screws are used for attaching the plasterboard sheets to the top plates around the edges. Different spacings of the roof joists/trusses could result in different equivalent shear moduli from the reported values in Table 5, however the effect is believed to be insignificant. This is because a smaller spacing of the roof joists/trusses would lead to higher shear stiffness, and vice versa. However the contribution of shear-related stiffness to the overall stiffness of the plasterboard ceiling diaphragms is significantly smaller than that of screw slips. 
Table 5: Estimated equivalent shear moduli, $G_{e}$.

\begin{tabular}{cccc}
$\begin{array}{c}\text { In-plane } \\
\text { translation } \\
\mathbf{m m}\end{array}$ & $\begin{array}{c}\mathbf{G}_{\mathrm{e}}(\mathrm{Detail} \mathbf{A}) \\
(\mathrm{MPa})\end{array}$ & $\begin{array}{c}\mathbf{G}_{\mathrm{e}}(\text { Detail B) } \\
(\mathrm{MPa})\end{array}$ & $\begin{array}{c}\mathrm{G}_{\mathrm{e}}(\text { Detail } \mathbf{C}) \\
(\mathrm{MPa})\end{array}$ \\
\hline 0.5 & 450 & 7500 & 97 \\
1 & 370 & 6167 & 80 \\
1.6 & 300 & 5000 & 65 \\
2.75 & 220 & 3667 & 47 \\
4.5 & 160 & 2667 & 35 \\
5 & 140 & 2333 & 30 \\
6 & 110 & 1833 & 24 \\
\hline
\end{tabular}

\section{CONCLUSIONS}

In this study, the in-plane behaviour of plasterboard sheathed ceiling diaphragm following NZ code requirements and common practice was experimentally evaluated. A test program consisting of one full-scale ceiling diaphragm specimen and three small-scale ceiling diaphragm specimens was undertaken. The effects of commonly used construction details on the diaphragm stiffness were studied. Based on the testing results, a simplified analytical model with calibrated equivalent shear rigidity of the diaphragm was developed for the plasterboard ceiling diaphragms.

The main conclusions of this study are:

- Under in-plane loading, the entire plasterboard linings of a plasterboard ceiling diaphragm behave like one monolithic plate.

- Under in-plane loading, up to $80 \%$ of total in-plane deformation is due to the slips of screw fixings between the plasterboard linings to the frames.

- Stiffness degradation of the plasterboard ceiling diaphragm is very significant with the loading progresses.

- The deep beam analogical method in NZS3603 to predict in-plane deflection of timber floor diaphragms can be used in estimating the in-plane stiffness of plasterboard ceiling diaphragms, if the screw slip model is adequate.

- The analytical model developed for plasterboard ceiling diaphragms in this study could capture non-linear in-plane behaviour of plasterboard ceiling diaphragms, similar to the bracing model developed for plasterboard wall elements in the accompanying paper. With these two developed models, three-dimensional non-linear seismic analyses of irregular LTF buildings could be conducted to quantify the seismic effects of the currently permissible irregularity of NZS3604 and help make informed changes if necessary.

\section{ACKNOWLEDGEMENTS}

This research project was funded by the Building Research Levy.

\section{REFERENCES}

1 Standards New Zealand (2011). "NZS 3604 Timber-framed Buildings". Standards New Zealand, Wellington.

2 Liu A and Carradine D (2019). "Seismic Bracing Performance of Plasterboard Timber Walls". Bulletin of the NZ Society for Earthquake Engineering, 52(2): 56-66, DOI: 10.5459/bnzsee.52.2.56-66.

3 Liu A and Beattie G (2012). "Influence of Stiffness Variation on the Performance of Houses in Earthquakes".
Proceedings of the 2012 NZSEE Annual Conference, Christchurch, NZ, 13-15 April, Paper 113.

4 Shelton R (2013). "Engineering Basis of NZS 3604". BRANZ Ltd, Judgeford, NZ. http://www.branz.co.nz/Engineering_Basis_of_NZS_3604

5 Liu A (2017). "The Need for a Systematic Approach in Damage Control Design for Light Timber-Framed Buildings in Earthquakes". Proceedings of the $16^{\text {th }}$ World Conference on Earthquake Engineering, Santiago, Chile, $9^{\text {th }}-13^{\text {th }}$ January, Paper $N^{\circ} 1279$.

6 Canterbury Earthquakes Royal Commission. (2012). "Final Report: Volume 2: The Performance of Christchurch CBD Buildings".

https://canterbury.royalcommission.govt.nz/vwluResource s/FinalReportVol2Print/\$file/Final_Report_Volume_2_W eb.pdf

7 Carradine DM, Dolan JD and Butt JW (2004). "Effect of Load and Construction on Cyclic Stiffness of Wood Diaphragms". Proceedings of the World Conference on Timber Engineering, Lahti, Finland, 14-17 June, 6p.

8 Kirkham WJ, Miller TH and Gupta R (2016). "Practical Analysis for Horizontal Diaphragm Design of Wood-Frame Single-Family Dwellings". Practice Periodical on Structural Design and Construction, 21(1): 04015005.

9 Lucksiri K, Miller T, Gupta R, Pei S and van den Lindt J (2012). "Effect of plan configuration on seismic performance of single-storey wood-frame dwellings". Natural Hazards Review, 13(1): 24-33.

10 Saifullah I (2016). "Performance of Ceiling Diaphragms in Steel-Framed Domestic Structures Subjected to Wind Loading". $\mathrm{PhD}$ Thesis, Swinburne University of Technology, Hawthorn, Australia.

11 Liu A and Shelton R (2018). "Seismic Effects of Structural Irregularity of Light Timber-framed Buildings". BRANZ Study Report SR404, BRANZ Ltd, Judgeford, NZ.

12 Shelton R (2004). "Diaphragms for timber framed buildings". SESOC Journal, 17(1): 16-23.

13 WWB (2014). "GIB Site Guide". Winstone Wallboards Limited, Auckland, NZ, 111p.

14 Thurston S (1993). "Report on Racking Resistance of Long Sheathed Timber Framed Walls with Openings". BRANZ Study Report SR54. BRANZ Ltd, Judgeford, NZ.

15 Sinha A and Gupta R (2009). "Strain Distribution in OSB and GWB in Wood-Frame Shear Walls". Journal of Structural Engineering, 135(6): 666-675.

16 NZS3603 (1993). “Timber Structures Standard”. Standards New Zealand, Wellington, NZ.

17 Saifullah I, Gad E, Shahi R and Watson K (2016). "Structural behaviour of ceiling diaphragms in steel-framed residential structures". Proceedings of the Australasian Structural Engineering Conference: ASEC 2016, Brisbane, Australia, 22-25 November.

18 Dowrick DJ and Smith PC (1986). "Timber Sheathed Wall for Seismic and Wind Resistance". Bulletin of the NZ National Society for Earthquake Engineering, 19(2): 123134.

19 Kamiya F (1990). "Horizontal plywood sheathed diaphragms with openings: Static loading tests and analysis". Proceedings, of the 1990 International Timber Engineering Conference, Tokyo, Japan.

20 Moroder D (2016). "Floor Diaphragms in Multi-Storey Timber Buildings". PhD Thesis, University of Canterbury, Christchurch, NZ. 